\title{
Cluster headache associated with moyamoya
}

\author{
R. Andrew Sewell · Daren M. Johnson • \\ Douglas W. Fellows
}

Received: 18 August 2008/Accepted: 21 October 2008/Published online: 14 November 2008

(C) Springer-Verlag 2008

\begin{abstract}
A 34-year-old man with right-sided cluster headache presented with a stroke from right-sided moyamoya. Following surgery on the right, both moyamoya and cluster headache remitted, but eighteen months later a cluster attack and symptoms of cerebral ischemia from moyamoya recurred on the left. Again, following surgery on the left, both moyamoya symptoms and cluster attacks disappeared. Cluster headache secondary to moyamoya has not previously been described.
\end{abstract}

Keywords Cluster headache $\cdot$ Moyamoya

\section{Introduction}

Moyamoya disease is a chronic cerebrovascular occlusive disease characterized by stenosis or occlusion of the terminal portions of the bilateral internal carotid arteries and particular involvement of the circle of Willis and the arteries that feed it. The term moyamoya (Japanese for

Electronic supplementary material The online version of this article (doi:10.1007/s10194-008-0081-3) contains supplementary material, which is available to authorized users.

\section{R. A. Sewell $(\square)$}

Department of Psychiatry, VA Connecticut

Healthcare/Yale University School of Medicine,

950 Campbell Ave., Building 36,

West Haven, CT 06516, USA

e-mail: asewell71@gmail.com

D. M. Johnson

Wichita, KS 67209, USA

D. W. Fellows

Diagnostic Imaging and Therapeutics, University of Connecticut Health Science Center, Farmington, CT 06030, USA "puff of smoke") describes the appearance on angiography of abnormal collateral vascular networks that develop adjacent to the stenotic vessels. It may result in ischemic attacks, cerebral infarction, or cerebral hemorrhage. Headache is a common symptom, but these have until now uniformly been described as migrainous (Goadsby, Sakai, personal communications). Cluster headache secondary to moyamoya has not previously been described.

\section{Case report}

A 34-year-old-man with cluster headache since age 18 had had cluster periods occurring for 4 months each year, usually in spring but occasionally during the autumn instead, characterized by three to seven right-sided cluster attacks per day that were ten out of ten in pain intensity, and associated with rhinorrhea, lacrimation, and ptosis. During an attack he would roll around on the floor, compulsively pound his head, and scream short phrases such as "why me?" Mostly nocturnal, the attacks lasted 1.5-2 h if untreated, but responded well to oxygen in $20 \mathrm{~min}$ and sumatriptan within minutes. Prophylactic medications such as ergotamine, propanolol, methysergide, verapamil, and divalproex were all ineffective, however. During a cluster period, sleep deprivation led to reassignment of duties when he was in the Army and decreased job performance in civilian life, but did not otherwise impact his personal relationships or academic performance. He has never had a fundoscopic exam. He has smoked 1.5 packs a day since age 19 and drinks a 12-pack of beer a week, but has never used any illegal drugs except for occasional marijuana prior to 1988 when he joined the military.

At age 34, he presented with unilateral left-sided restless legs syndrome (RLS) and numbness in the fingers 
Fig 1 a Lateral view from a selective right internal carotid angiogram shows occlusion of the supraclinoid ICA with "puff of smoke" from basal collateral vessels. b, d 3-D volume rendered SPECT images prior to surgical intervention demonstrate profound hypoperfusion in the right middle cerebral arterial distribution. c, e Images obtained following STA-MCA bypass show virtually normal and symmetric perfusion

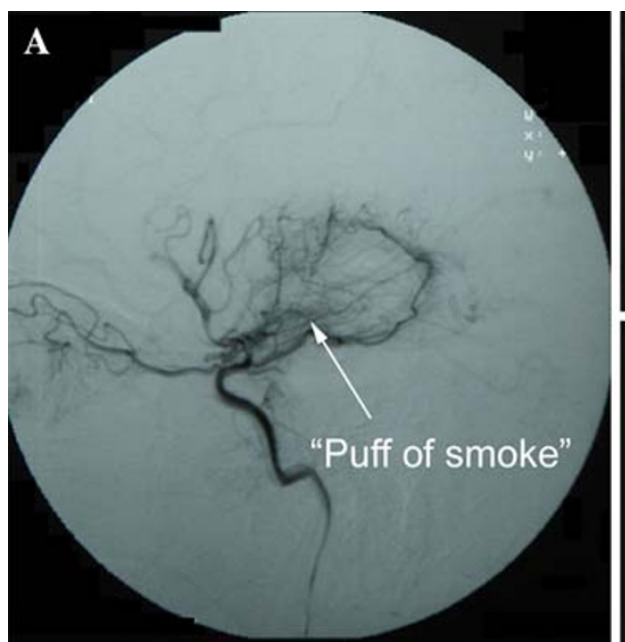

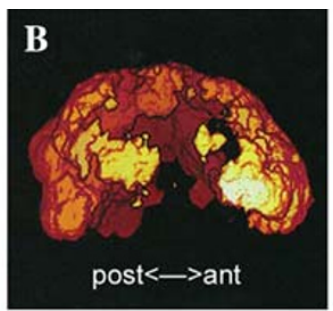

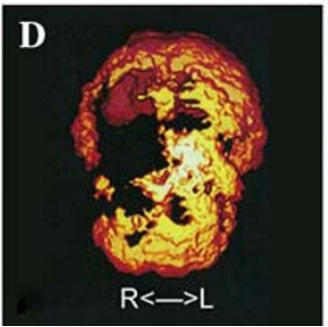

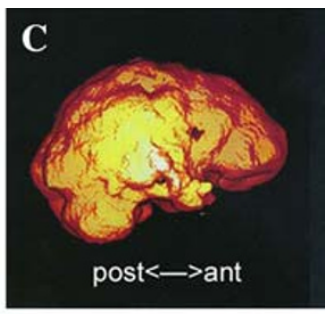

E

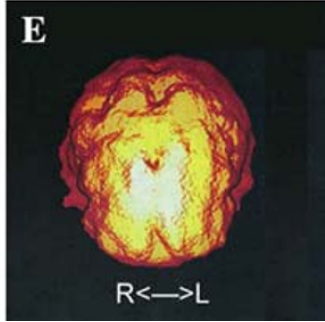

of his left hand that was permanent in one finger but fluctuated throughout the day in the others. He was diagnosed with a stroke from moyamoya (Fig. 1a). Following a right-sided superior temporal artery (STA) to middle cerebral artery (MCA) bypass three months later, his cerebral perfusion improved (Before: Fig. 1b, d; After: Fig. 1c, e) and his RLS and cluster attacks remitted. Eighteen months later, however, he experienced his first, solitary cluster attack on the left-all previous attacks having been on the right-followed shortly thereafter by return of his RLS and finger numbness, this time on the right. Imaging confirmed a worsening of his left-sided moyamoya, and he underwent a left STA-MCA bypass (video 1). Six years later, he has had no further cluster attacks.

\section{Discussion}

Although correlation does not imply causation, the temporal and lateral concordance of both cluster headache and moyamoya symptoms are consistent with such a relationship. Twice, cluster headache symptoms occurred contralateral to the moyamoya symptoms (in the ipsilateral hemisphere), and each time, cluster headache symptoms remitted with successful treatment of the moyamoya.

Secondary, or symptomatic cluster headache has been described from pituitary adenoma [1,2], meningiomas of the sphenoid wing [3], upper cervical area [4], and undersurface of the tentorium cerebelli [5] (where inflammatory myofibroblastic tumor has also caused cluster headache) [6], aneurysms of the anterior cerebral [1], posterior cerebral [7], vertebral [8], and carotid arteries [1], dissections of the vertebral [9] and internal carotid arteries $[10,11]$, arteriovenous malformations in the middle cerebral artery [12] as well as occipital [13], frontal, temporal, and parietotemporal lobes [14-16], Wallenberg's syndrome [17], pituitary orbitosphenoidal aspergillosis [18], head and neck injury [19], ipsilateral enucleation [20], calcified lesions close to the third ventricle [21], cavernous sinus granulomatous tissue [22], and post carotid endarterectomy [23, 24].

Most symptomatic cases are from lesions located near the midline in the middle fossa of the skull base, although lesions involving structures that are innervated by branches of $\mathrm{C} 2$ can trigger cranial autonomic activation in humans [25] and animals [26], and C2 activation can sensitize trigeminal neurons that receive input from incracranial vessels [27]. Disturbance of sympathetic nerve function, either in the plexus of parasympathetic, sympathetic, and sensory fibers in the connective tissue of the cavernous sinus/hypophyseal region or in the walls of the internal carotid artery is known to generate cluster headache, and it is possible that the progressive intimal thickening in the carotid walls of this patient and consequent sympathetic disruption exacerbated his attacks.

Acknowledgments The authors would like to thank Bob Wold of the Clusterbusters for referring to us the case. Funding was provided by a grant from the Mental Illness Research, Education \& Clinical Center (MIRECC) at the United States Department of Veterans Affairs.

Conflict of interest None.

\section{References}

1. Greve E, Mai J (1988) Cluster headache-like headaches: a symptomatic feature? A report of three patients with intracranial pathologic findings. Cephalalgia 8(2):79-82

2. Tfelt-Hansen P, Paulson OB, Krabbe AA (1982) Invasive adenoma of the pituitary gland and chronic migrainous neuralgia. A rare coincidence or a causal relationship? Cephalalgia 2(1):25-28

3. Hannerz J (1989) A case of parasellar meningioma mimicking cluster headache. Cephalalgia 9(4):265-269 
4. Kuritzky A (1984) Cluster headache-like pain caused by an upper cervical meningioma. Cephalalgia 4(3):185-186

5. Bigal ME, Rapoport AM, Camel M (2003) Cluster headache as a manifestation of intracranial inflammatory myofibroblastic tumour: a case report with pathophysiological considerations. Cephalalgia 23(2):124-128

6. Taub E, Argoff CE, Winterkorn JM, Milhorat TH (1995) Resolution of chronic cluster headache after resection of a tentorial meningioma: case report. Neurosurgery 37(2):319-321 (discussion 21-2)

7. McBeath JG, Nanda A (2000) Case reports: sudden worsening of cluster headache: a signal of aneurysmal thrombosis and enlargement. Headache 40(8):686-688

8. West P, Todman D (1991) Chronic cluster headache associated with a vertebral artery aneurysm. Headache 31(4):210-212

9. Cremer PD, Halmagyi GM, Goadsby PJ (1995) Secondary cluster headache responsive to sumatriptan. J Neurol Neurosurg Psychiatry 59(6):633-634

10. Frigerio S, Buhler R, Hess CW, Sturzenegger M (2003) Symptomatic cluster headache in internal carotid artery dissectionconsider anhidrosis. Headache 43(8):896-900

11. Rosebraugh CJ, Griebel DJ, DiPette DJ (1997) A case report of carotid artery dissection presenting as cluster headache. Am J Med 102(4):418-419

12. Muoz C, Diez-Tejedor E, Frank A, Barreiro P (1996) Cluster headache syndrome associated with middle cerebral artery arteriovenous malformation. Cephalalgia 16:202-205

13. Mani S, Deeter J (1982) Arteriovenous malformation of the brain presenting as a cluster headache - a case report. Headache 22(4):184-185

14. Gawel MJ, Willinsky RA, Krajewski A (1989) Reversal of cluster headache side following treatment of arteriovenous malformation. Headache 29(7):453-454

15. Hindfelt B, Olivecrona H (1991) Cerebral arteriovenous malformation and cluster-like headache. Headache 31(8):514-517

16. Molins A, Lopez M, Codina A, Titus F (1989) Symptomatic cluster headache? Apropos of four case reports. Medi Clin 92(5):181-183
17. Cid CG, Berciano J, Pascual J (2000) Retro-ocular headache with autonomic features resembling "continuous" cluster headache in lateral medullary infarction. J Neurol Neurosurg Psychiatry 69(1): 134

18. Heidegger S, Mattfeldt T, Rieber A, Wikstroem M, Kern P, Kern $\mathrm{W}$ et al (1997) Orbito-sphenoidal Aspergillus infection mimicking cluster headache: a case report. Cephalalgia 17(6):676-679

19. Hunter CR, Mayfield FH (1949) Role of the upper cervical roots in the production of pain in the head. Am J Surg 78(5):743-751

20. Levyman C, Dagua Filho Ados S, Volpato MM, Settanni FA, de Lima WC (1991) Epidermoid tumour of the posterior fossa causing multiple facial pain-a case report. Cephalalgia 11(1):33-36

21. Narbone MC, D'Amico D, Di Maria F, Arena MG, Longo M (1991) Cluster-like headache and a median intracranial calcified lesion: case report. Headache 31(10):684-685

22. Gobel I, Trendelenburg AU, Cox SL, Meyer A, Starke K (2000) Electrically evoked release of $[(3) \mathrm{H}]$ noradrenaline from mouse cultured sympathetic neurons: release-modulating heteroreceptors. J Neurochem 75(5):2087-2094

23. De Marinis M, Zaccaria A, Faraglia V, Fiorani P, Maira G, Agnoli A (1991) Post-endarterectomy headache and the role of the oculosympathetic system. J Neurol Neurosurg Psychiatry 54(4):314-317

24. Bjorne A, Hindfelt B, Havelius U (1994) Recurrence of cluster headache after carotid thrombendarterectomy. Headache 34(4):230-233

25. Warner JS, Wamil AW, McLean MJ (1994) Acetazolamide for the treatment of chronic paroxysmal hemicrania. Headache 34(10):597-599

26. Goadsby PJ, Edvinsson L (1996) Neuropeptide changes in a case of chronic paroxysmal hemicrania-evidence for trigeminoparasympathetic activation. Cephalalgia 16(6):448-450

27. MacMillan JC, Nukada H (1989) Chronic paroxysmal hemicrania. The New Zealand Med J 102(868):251-252 